\title{
Integration of GLAS and Landsat TM data for aboveground biomass estimation
}

\author{
L.I. Duncanson, K.O. Niemann, and M.A. Wulder
}

\begin{abstract}
Current regional aboveground biomass estimation techniques, such as those that require extensive fieldwork or airborne light detection and ranging (lidar) data for validation, are time and cost intensive. The use of freely available satellite-based data for carbon stock estimation mitigates both the cost and the spatial limitations of field-based techniques. Spaceborne lidar data have been demonstrated as useful for aboveground biomass (AGBM) estimation over a wide range of biomass values and forest types. However, the application of these data is limited because of their spatially discrete nature. Spaceborne multispectral sensors have been used extensively to estimate AGBM, but these methods have been demonstrated as inappropriate for forest structure characterization in high-biomass mature forests. This study uses an integration of ICESat Geospatial Laser Altimeter System (GLAS) lidar and Landsat data to develop methods to estimate AGBM in an area of south-central British Columbia, Canada. We compare estimates with a reliable AGBM map of the area derived from high-resolution airborne lidar data to assess the accuracy of satellite-based AGBM estimates. Further, we use the airborne lidar dataset in combination with forest inventory data to explore the relationship between model error and canopy height, AGBM, stand age, canopy rugosity, mean diameter at breast height (DBH), canopy cover, terrain slope, and dominant species type. GLAS AGBM models were shown to reliably estimate AGBM $\left(R^{2}=0.77\right)$ over a range of biomass conditions. A partial least squares AGBM model using Landsat input data to estimate AGBM (derived from GLAS) had an $R^{2}$ of 0.60 and was found to underestimate AGBM by an average of $26 \mathrm{Mg} / \mathrm{ha}$ per pixel when applied to areas outside of the GLAS transect. This study demonstrates that Landsat and GLAS data integration are most useful for forests with less than $120 \mathrm{Mg} /$ ha of AGBM, less than 60 years of age, and less than $60 \%$ canopy cover. These techniques have high associated error when applied to areas with greater than $200 \mathrm{Mg} / \mathrm{ha}$ of AGBM.
\end{abstract}

Resume. Les techniques actuelles d'estimation de la biomasse aérienne à l'échelle régionale, telles que celles qui requièrent beaucoup de travail de terrain ou des données lidar ( "light detection and ranging ») aéroportées pour validation, sont onéreuses en termes de temps et de coûts. L'utilisation de données satellite disponibles gratuitement pour l'estimation des stocks de carbone permet de pallier les coûts et les limitations spatiales liés aux techniques basées sur les campagnes de terrain. L'utilité des données satellite lidar a été démontrée pour l'estimation de la biomasse aérienne (AGBM) et ce pour une grande variété de valeurs de biomasse et de types de forêts. Toutefois, l'application de ces données est limitée en raison de la nature spatialement discrète de ces dernières. Les capteurs satellitaires multispectraux ont été utilisés largement pour estimer l'AGBM, mais ces méthodes se sont avérées inappropriées pour la caractérisation de la structure de la forêt dans les forêts de forte biomasse et matures. La présente étude utilise une intégration des données du système GLAS («Geospatial Laser Altimeter System ») de ICESAT ainsi que des données lidar et de Landsat pour développer des méthodes pour l'estimation de l'AGBM dans un secteur du centre sud de la Colombie-britannique, au Canada. On compare ces estimations par rapport à une carte fiable de l'AGBM pour la zone dérivée des données lidar aéroportées à haute résolution afin d'évaluer la précision des estimations de l'AGBM basées sur les données satellite. De plus, on utilise l'ensemble de données lidar aéroportées en combinaison avec des données d'inventaire forestier pour documenter la relation entre l'erreur liée au modèle et la hauteur du couvert, l'AGBM, l'âge du peuplement, la rugosité du couvert, le DHP moyen, la nature du couvert, la pente du terrain et le type d'espèces dominantes. Les modèles d'AGBM de GLAS ont démontré leur fiabilité dans l'estimation de l'AGBM $\left(R^{2}=0,77\right)$ dans une variété de conditions de biomasse. Un modèle des moindres carrés partiels de l'AGBM utilisant comme données d'entrée des données de Landsat pour estimer l'AGBM (dérivée de GLAS) affichait un $R^{2}$ de 0,60 et on a pu observer qu'il sous-estime l'AGBM par en moyenne $26 \mathrm{Mg} / \mathrm{ha}$ par pixel lorsqu'on l'applique dans des zones à l'extérieur du transect de GLAS. Cette étude a démontré que l'intégration des données de Landsat et de GLAS est très utile pour les forêts ayant moins de $120 \mathrm{Mg} / \mathrm{ha}$ d'AGBM, moins de soixante ans d'âge et moins de $60 \%$ de couvert. Ces techniques présentent des erreurs associées élevées lorsque appliquées dans des zones avec plus de $200 \mathrm{Mg} / \mathrm{ha}$ d'AGBM.

[Traduit par la Rédaction]

Received 2 November 2009. Accepted 18 May 2010. Published on the Web at http://pubservices.nrc-cnrc.ca/cjrs on 24 September 2010.

L.I. Duncanson and K.O. Niemann. ${ }^{1}$ Hyperspectral - LiDAR Research Group, Department of Geography, University of Victoria, Victoria, BC V8W 3R4, Canada.

M.A. Wulder. Canadian Forest Service (Pacific Forestry Centre), Natural Resources Canada, Victoria, BC V8Z 1M5, Canada.

${ }^{1}$ Corresponding author (e-mail: olaf@uvic.ca). 


\section{Introduction}

The need exists to develop a systematic approach to inventory and monitor global forests, both for carbon stock evaluation and for land use change analysis (Rosenqvist et al., 2003). Carbon stock estimation is also important given the development of international carbon credit trading schemes, which can be utilized to reduce deforestation and degradation, particularly in developing nations (Gibbs et al., 2007). Remote sensing provides the ability to collect data from remote forested areas that would otherwise be costly and logistically difficult to collect. Various remote sensing technologies have been demonstrated as useful for different aspects of forest research. Airborne hyperspectral remote sensing instruments have been demonstrated to provide highly accurate information pertaining to species type and composition (Clark et al., 2005; Van Aardt and Wynne, 2007), and airborne light detection and ranging (lidar) instruments provide the ability to accurately estimate tree height (Means et al., 1999), volume, and aboveground biomass (AGBM) or carbon content (Patenaude et al., 2004; Nelson et al., 2003). As such, technologies are available that can be used to study a forest's interaction with light and its physical structure. However, these airborne technologies have high associated data volumes and costs (Wulder et al., 2008). Consequently, they are best suited for studying forests over relatively small, localized areas or for use in sampling strategies (Wulder and Seemann, 2003).

Satellite-based remote sensing technologies provide the ability to collect data over regional, national, and global scales. Multispectral satellite data, such as those collected by the Landsat Thematic Mapper (TM), have been widely used for landscape classification and change detection in forested areas (Wulder, 1998). Studying forest structural properties with multispectral data is more problematic, although many studies have attempted to model forest structural parameters using multispectral imagery with varying levels of success (Hall et al., 1995; Cohen and Spies, 1992; Cohen et al., 2003; Zheng et al., 2004). The normalized difference vegetation index (NDVI) and tassel cap transformations are two of the most common types of vegetation indices used in multispectral studies of forest structure (Rogan et al., 2002). Freitas et al. (2005) found that forest structural properties could be estimated using Landsat-derived vegetation indices $R^{2}=0.49-0.72$ ) for a tropical rainforest. Zheng et al. (2004) modeled AGBM in a managed forest in Wisconsin with Landsat 7 Enhanced Thematic Mapper Plus (ETM+) data $\left(R^{2}=0.67\right)$. Hall et al. (2006) found that stand height $\left(R^{2}=0.65\right)$ and crown closure $\left(R^{2}=0.57\right)$ could also be estimated from Landsat ETM+ data in an area of Alberta with forest cover similar to that of the study area used in this research.

Collinearity is a common issue when using vegetation indices in combination with raw Landsat bands (Hensen and Schjoerring, 2003). One method to extract the most meaningful information from multispectral data is partial least squares (PLS) regression. Collinearity and data dimensionality reduce the utility of ordinary least squares (OLS) regression (Hensen and Schjoerring, 2003), and PLS regression is one statistical technique that can be used to mitigate this problem (Næsset et al., 2004). PLS involves the extraction of linear combinations of the original input variables and produces a new set of variables than can then be used to model the desired output, in this case AGBM. PLS has been demonstrated as useful for studies of biomass using optical data (Cai et al., 2009; Hensen and Schjoerring, 2003).

Despite attempts to model biomass directly from Landsat data, studies have demonstrated that models developed to estimate forest structure from multispectral data are sensitive to tree height (Donoghue and Watt, 2006), shadows (Hall et al., 1995), and high biomass densities (Foody et al., 2001). Thus, although the spatially continuous nature of optical satellite imagery renders it ideal for studying phenomena over large areas, regional analyses of forest structural properties require information about the vertical distribution of biomass in a forest. Studies using optical imagery to model such vertical properties are limited because optical data integrate the vertical profile of a forest into a single reflectance value per pixel (Hall et al., 1995).

Satellite-based lidar provides an opportunity to accurately estimate AGBM from space. Recent studies have focused on using spaceborne lidar data to accurately model forest height and AGBM. The National Aeronautics and Space Administration (NASA) Geospatial Laser Altimeter System (GLAS) instrument onboard ICESat is a full-waveform satellite-based lidar system with a $65 \mathrm{~m}$ diameter footprint (Schutz et al., 2005). The returned waveforms from these footprints can be used to estimate tree height, AGBM, and basal area (Lefsky et al., 2007; Sun et al., 2008; Ranson et al., 2007; Rosette et al., 2008). The accuracy of these models was found to depend on both canopy density and terrain slope. Increasing density and slope increase the complexity of GLAS waveform footprints, and in high-relief or highbiomass areas it can be difficult to resolve ground reflection from canopy reflection within waveforms. This confusion can be reduced through the introduction of ground filtering techniques. Duncanson et al. (2010) developed a methodology to estimate and account for terrain relief in GLAS AGBM estimates and determined that adjusting for terrain relief increases the accuracy of GLAS AGBM models.

A number of issues render GLAS data less than ideal for large-area forest inventories. The first is the limited nature of the data coverage. The design of the satellite orbit yields nearly contiguous coverage of the polar regions. The swaths diverge away from the poles, however, so other areas are covered by discrete orbits. Additionally, the GLAS laser samples along the flight path so that a $65 \mathrm{~m}$ diameter footprint is spaced every $172 \mathrm{~m}$. This sampling scheme yields an incomplete coverage. A second issue involves atmospheric noise. As lidar is a line-of-sight sensor, it is affected by clouds, and only cloud-free waveforms are appropriate for terrain analysis. Lastly, because of technological issues early 
in the GLAS mission, GLAS does not continually sense the Earth's surface but instead operates in three annual 33 day campaigns (Schutz et al., 2005). Considering these limitations, the GLAS data available from the National Ice and Snow Data Distribution Centre (NISDC) are not spatially continuous but represent a series of transects. The distribution of footprints available from any region depends largely on the location of the region and the atmospheric conditions at the time of GLAS passage. Although GLAS data have the potential to be useful for the estimation of AGBM and carbon content of forests, these logistics limit the applicability of GLAS-derived models for regional biomass mapping.

Integrating the two-dimensional, spatially continuous data from Landsat TM with the three-dimensional, spatially discrete GLAS data may provide a systematic method to estimate AGBM over large areas, on regional, national, and even global scales. Studies have integrated passive optical and lidar technology in attempts to either extrapolate lidar forest structure measurements to areas with spectral properties similar to those sensed by lidar (Hudak et al., 2002; Donoghue and Watt, 2006) or more meaningfully interpret results from lidar studies (Wulder et al., 2007). This study employs a regression-based AGBM modeling approach similar to those used in other Landsat AGBM studies. This approach was selected because it does not rely on field data and can be applied using only freely available satellite data. The availability of high-resolution airborne lidar data and a current forest inventory for the entire study area allows us to evaluate the accuracy of Landsat and GLAS integration AGBM estimates on a pixel-by-pixel basis. This allows the comparison of model error with terrain characteristics to improve our understanding of the utility of these methods. The objectives of this study are to (i) develop a method to model AGBM from GLAS and Landsat integration; (ii) determine the relationships between model error and forest cover properties, such as dominant species and stand age; and (iii) establish reliable ranges of forest structural properties for which GLAS and Landsat data integration is appropriate for AGBM estimation.

\section{Methods}

\section{Study area}

Airborne lidar data were acquired for a 75000 ha area of industrially managed forest near Clearwater, British Columbia, Canada. The one quality GLAS laser 3 transect available for the area was selected for use in this study (Figure 1). The predominant species in the area are lodgepole pine (Pinus contorta), balsam fir (Abies balsamea), Douglas-fir (Pseudotsuga menziesii), western hemlock (Tsuga heterophylla), western redcedar (Thuja plicata), Engelmann spruce (Picea engelmannii), and white spruce (Picea glauca) (Pedersen and Forester, 2000). The area is characterized as a highelevation plateau of gently rolling terrain with an elevation range of approximately $800 \mathrm{~m}$ (Pedersen and Forester, 2000).

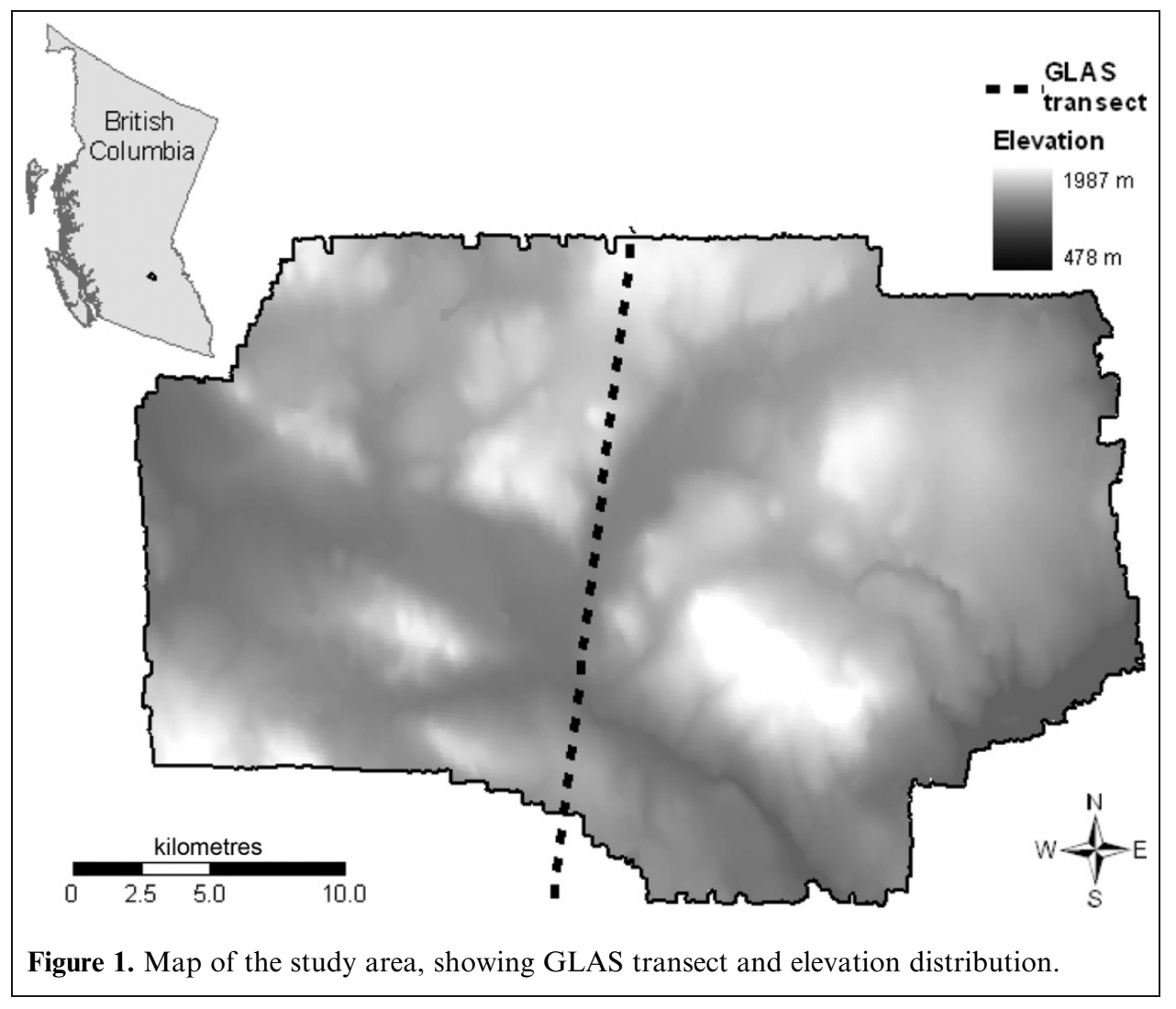




\section{Airborne lidar data}

Airborne scanning laser lidar data were acquired in August 2006 using the University of Victoria TERRA Multisensor Airborne Platform (MAP). This system has an integrated lidar and full-range (400-2500 $\mathrm{nm}$ ) hyperspectral imaging system. The data used for this project consist of discrete, first- and last-return $100 \mathrm{kHz}$ lidar data with a maximum scan angle of $\pm 20^{\circ}$ and a scanning speed of $37 \mathrm{~Hz}$. The pulse repetition frequency (PRF) of the dataset used was $60 \mathrm{kHz}$. The platform was flown $1600 \mathrm{~m}$ above ground, which in combination with the PRF resulted in approximately 1.25 points per square metre at nadir and 2.25 lidar returns per square metre when side overlap was included. Processing was conducted to separate ground returns from those of vegetation. Bare-earth and canopy-height models (CHM) were subsequently generated; the CHM heights were calculated as the difference between the elevation of a return and the coincident elevation of the bare-earth model. These data were also used to calculate terrain slope and rugosity (standard deviation) of hits height which were used to explore model results.

\section{Field data}

Field data were collected during a 4 day period in October 2008. Diameter at breast height (DBH), tree species, and tree height were measured for every tree within a $10 \mathrm{~m}$ diameter plot for 35 plots representative of the cover classes found in the study area. Plots were positioned to within $2 \mathrm{~m}$ absolute accuracy using a post-processed differential global positioning system (GPS).

\section{AGBM map}

An ordinary-least squares regression was fit between fieldestimated AGBM and a series of airborne lidar measurements. The natural logarithm of the total AGBM (dry weight) was found to be a function of the natural logarithms of the 55th percentile of laser canopy height $\left(\mathrm{Lh}_{0.55}\right)$ and laser canopy cover (CC; the percentage of all laser returns found at canopy heights $\geq 2 \mathrm{~m}$ ):

$\ln \mathrm{TAGB}=0.0914+1.0496 \ln \mathrm{Lh}_{0.55}+0.5719 \ln \mathrm{CC}$

where TAGB is the total AGBM (dry weight, in $\mathrm{Mg} / \mathrm{ha}$ ). The fitted model produced an $R^{2}$ value of 0.89 , a root mean square error (RMSE) of $46.07 \mathrm{Mg} / \mathrm{ha}$, and a mean bias of $2.38 \mathrm{Mg} / \mathrm{ha}$. Back-transformation of the fitted regression model to arithmetic units was accomplished following the procedures of Sprugel (1983). To estimate AGBM in the field, species-specific allometric equations were used as presented by Jenkins et al. (2003). Because generalized allometric equations were used to estimate AGBM on a per tree (dry weight) basis (Jenkins et al., 2003) from field data, we expect that this dataset will have a larger RMSE and bias compared with those of locally acquired allometric equations (Hall and Case, 2008). Nevertheless, we expect these data to be sufficiently precise (Jenkins et al., 2003) for the purposes of calibration of our airborne lidar dataset.

This model was used to generate a spatially continuous, $20 \mathrm{~m} \times 20 \mathrm{~m}$ estimate of AGBM from the airborne lidar available for the area. This AGBM map, henceforth referred to as the AGBM control map, provides unique wide-area calibration-validation for AGBM estimates made using the GLAS and Landsat data.

\section{Satellite-based lidar}

GLAS is a full-waveform lidar sensor using a $1064 \mathrm{~nm}$ laser operating at $40 \mathrm{~Hz}$. The GLAS data used in this study were acquired on 26 June 2006 and represent a transect with 105 GLAS waveforms. This was the only temporally coincident transect available in the study site from GLAS laser 3 data. Laser 2 transects were available, but where laser 3 footprints approximate $65 \mathrm{~m}$ diameter circles, laser 2 footprints are more elliptical, and the spatial pattern of light reflection varies considerably between footprints. As such, the airborne lidar data could not be reliably matched to laser 2 footprints, and these were not included in the analysis. Details on the processing of these data can be found in Duncanson et al. (2010). A series of waveform metrics were calculated describing the shape of each waveform in terms of both their vertical (temporal) distribution and the energyreturn distribution. Table 1 provides a description of the waveform metrics used in this study.

\section{Satellite multispectral}

A single Landsat TM scene was selected for use in this study based on its temporal proximity to the acquisition of both the GLAS and airborne lidar data and based on the atmospheric conditions of the scene ( $<1 \%$ cloud). The image was acquired on 17 August 2006. It is unlikely that noteworthy change in AGBM occurred between the acquisition of the GLAS, airborne lidar, and Landsat datasets. We therefore assume that any change in AGBM between June and August of 2006 was negligible. Top-of-atmosphere correction was applied using the methodology presented in Han et al. (2007).

Table 1. Waveform metrics and abbreviations as outlined in Duncanson et al. (2010).

\begin{tabular}{|c|c|}
\hline $\begin{array}{l}\text { Metric } \\
\text { abbreviation }\end{array}$ & Description \\
\hline wf_max_e & Highest energy value in waveform \\
\hline wf_variance & Variance of waveform \\
\hline wf_skew & Skew of waveform \\
\hline e_44 & Proportion of energy in highest elevation quarter \\
\hline e_34 & $\begin{array}{l}\text { Proportion of energy in second highest elevation } \\
\text { quarter }\end{array}$ \\
\hline startpeak & $\begin{array}{l}\text { Difference in elevation between beginning of signal } \\
\text { and position of wf_max_e }\end{array}$ \\
\hline wf_n_gs & Number of Gaussian curves found in waveform \\
\hline
\end{tabular}




\section{Ancillary data map}

The British Columbia Vegetation Resources Inventory (VRI) (Ministry of Sustainable Resource Management, 2003) was used to explore the results found in this study. The variables explored using this inventory were canopy height, stand age, percent canopy cover, dominant species, and mean DBH.

\section{Analysis}

This study involved the development of several models to estimate AGBM from various sets of input data. First, a relationship was developed between field data and airborne lidar data, and a control AGBM map for the study area was generated. Second, the AGBM control map values were modeled from GLAS waveform metrics. Third, GLAS AGBM estimates were modeled from Landsat data. This third model is henceforth referred to as the Landsat-GLAS model. The GLAS estimates were modeled from Landsat rather than the more accurate AGBM control map values in an attempt to assess the accuracy of methods using only satellite data. The Landsat model was applied to the entire study area, and the differences between the observed (AGBM control map) values and the predicted (LandsatGLAS) values were evaluated for different species types and forest structural characteristics using forest inventory data and airborne lidar.

Successfully modeling AGBM from GLAS waveforms relied on the assumption that the AGBM control map could be manipulated to provide a single AGBM estimate for the $65 \mathrm{~m}$ diameter circle illuminated by each GLAS pulse. To achieve this, $65 \mathrm{~m}$ diameter circles, with centroids located at each GLAS centroid, were overlaid on the AGBM control map. The control map was translated into polygons, which were then clipped to the overlaid GLAS footprints. An average of 12 control map pixels fell within or partially within each GLAS footprint. A weighted average was used to calculate the average AGBM in megagrams per hectare for each GLAS footprint by multiplying each polygon's control map AGBM value by the area within the GLAS footprint, summing the resulting values for each footprint, and dividing by the area of the footprint. Thus, we generated a dataset representing a "control" value of AGBM for the area corresponding to each GLAS pixel.

These AGBM values were then root-transformed to reduce the positive skew of AGBM for the scene (Figure 2) and improve normality and linearity among variables. Following the methods presented in Duncanson et al. (2010), an ordinary least squares model was developed to predict these AGBM values from GLAS data. Binary-coded dummy variable GLAS waveform metrics were used to correct for terrain relief. Only variables with a correlation of less than 0.5 with any other input variable were used in this model. The dummy variables were coded based on maximum terrain relief estimated from GLAS waveform metrics, without reliance on ancillary topographic data, as outlined in Duncanson et al (2010). Dummy variables were used to adjust for different relationships between waveform metrics and

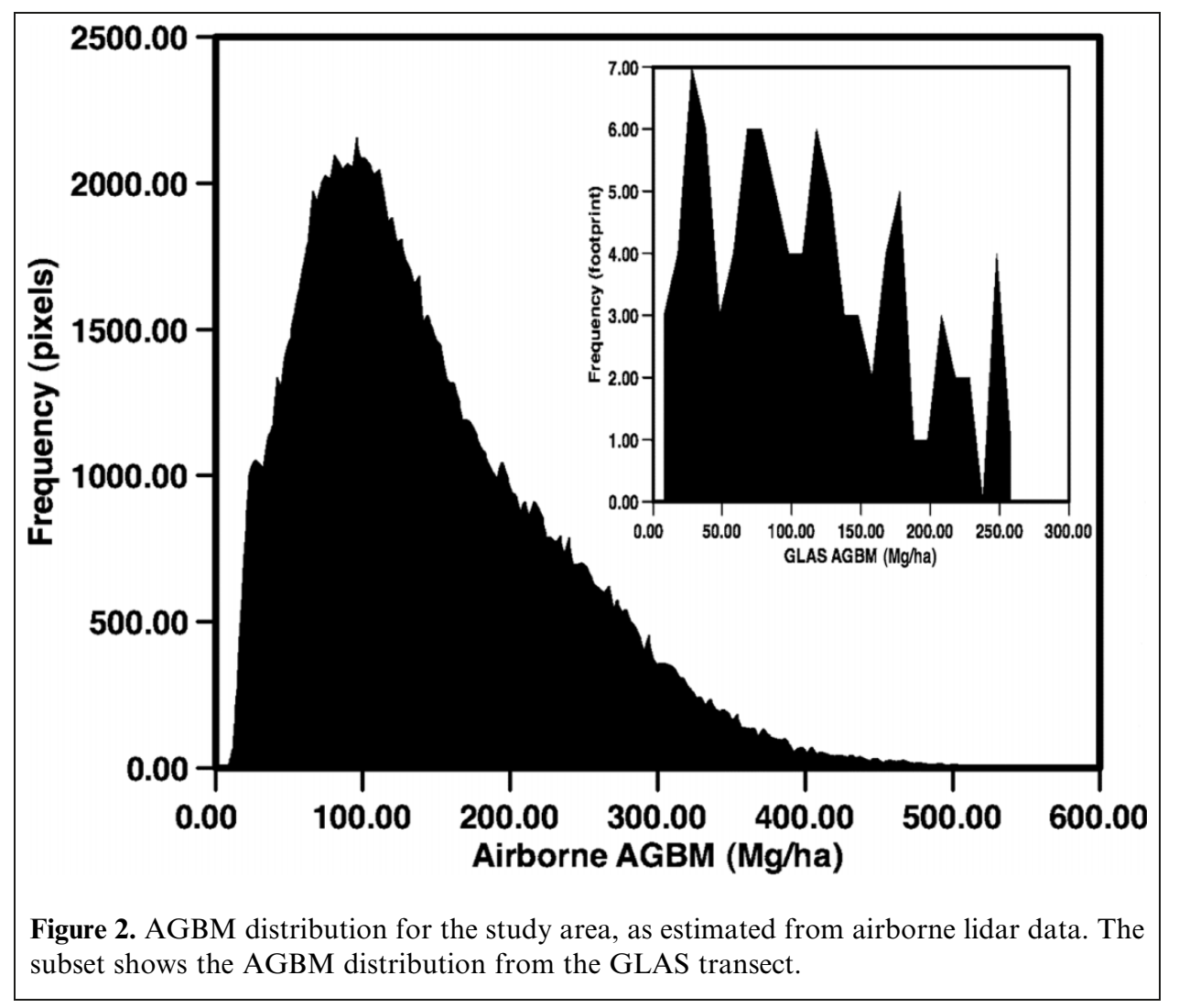


Vol. 36, No. 2, April/avril 2010

Table 2. AGBM model information.

\begin{tabular}{|c|c|c|c|}
\hline Model & Equation & $R^{2}$ & SE \\
\hline (1) GLAS & 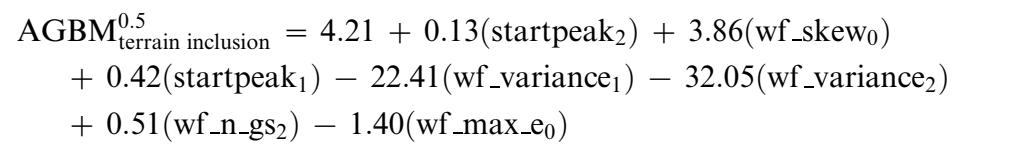 & 0.77 & 2.2 \\
\hline (2) Landsat-GLAS & $\begin{array}{l}\text { AGBM } \\
\quad 0.5 \\
\quad-51.58(\text { band } 4)+220.03(\text { band } 3)-312.80(\text { band } 2)+131.28(\text { band } 1)\end{array}$ & 0.60 & 2.0 \\
\hline
\end{tabular}

Note: All model coefficients are statistically significant to $95 \%$ confidence.

AGBM in flat (0-7 m), moderate-relief (7-15 m), or highrelief $(>15 \mathrm{~m})$ areas. The predictions from this model were squared to produce predictions of AGBM in megagrams per hectare for each GLAS footprint.

PLS regression was used to estimate the relationship of the Landsat data to the GLAS AGBM estimates. Due to the $65 \mathrm{~m}$ spatial resolution of the GLAS data, the Landsat image, AGBM map, and forest inventory map were resampled to $60 \mathrm{~m}$ pixels using nearest neighbour resampling. We rely on the assumption that the Landsat pixel coincident to a GLAS centroid location represents the multispectral response corresponding to a GLAS waveform. Landsat TM bands 1-5 and 7 and NDVI and three tassel cap transformation bands (brightness, greenness, wetness) were used as potential inputs into the PLS regression model to estimate the GLAS-predicted square root of AGBM. The best PLS model was applied to the entire study area, generating a spatially continuous $60 \mathrm{~m} \times 60 \mathrm{~m}$ Landsat-GLAS estimate map of AGBM (in $\mathrm{Mg} / \mathrm{ha}$ ).

The AGBM control map was subtracted from the Landsat-GLAS AGBM map. To ensure that only areas forested at the time of data acquisition were included in the study, the airborne lidar data were used to mask out zero AGBM pixels. The resulting error map, representing the overprediction and underprediction of AGBM for each pixel, was therefore masked for zero biomass.

The VRI maps of dominant species, canopy height, age, percent canopy cover, and mean DBH were used to decompose both the original AGBM map and the error map to explore differences in AGBM and error in areas of differing land cover. The mean observed AGBM (in $\mathrm{Mg} / \mathrm{ha}$ ), standard deviation of observed AGBM (in $\mathrm{Mg} / \mathrm{ha}$ ), and standard deviation of error (in $\mathrm{Mg} / \mathrm{ha}$ ) were calculated for the area associated with each dominant species (see Figure 5). Box and whiskers plots were created to visualize trends in error over increasing canopy height, AGBM, age, rugosity, mean DBM, percent canopy cover, and terrain slope (see Figure 6).

\section{Results}

\section{GLAS and Landsat-GLAS model results}

The results of the comparison of the predicted versus control biomass estimates are summarized in Table $\mathbf{2}$, and
Figure 3 shows the results of the GLAS model (model 1 in Table 2). Table 2 also summarizes the Landsat-GLAS PLS model (model 2), which estimates the predictions from the GLAS model (model 1). Figure 3 shows the results of both models 1 and 2, and Figure 4 shows the spatial distribution of the Landsat-GLAS estimates subtracting the AGBM control map. Three components, or latent variables, were used in the generation of the PLS model.

\section{Error image decomposition}

The standard deviation of model error for the study area was $89.3 \mathrm{Mg} / \mathrm{ha}$, the mean AGBM was $146.5 \mathrm{Mg} / \mathrm{ha}$, and the standard deviation of AGBM was $85.9 \mathrm{Mg} / \mathrm{ha}$. The error associated with the Landsat-GLAS model was decomposed based on terrain and forest cover characteristics derived from the airborne lidar data or the forest inventory. The standard deviation of error, mean AGBM, and standard deviation of AGBM related to the dominant species are shown in Figure 5. Douglas-fir, immature lodgepole pine, trembling aspen, birch, and paper birch are the species for which the standard deviation of error was greater than $100 \mathrm{Mg} / \mathrm{ha}$, well above the average error of $81.4 \mathrm{Mg} / \mathrm{ha}$. Douglas-fir had a high average AGBM and standard deviation of AGBM. The areas of immature lodgepole pine tended to be overestimated. Balsam fir, subalpine fir, and white spruce were the species for which the standard deviation of error was lowest.

Figure 6 shows the change in error mean, error median, error range, and 10th-90th percentiles of error with increasing canopy height, AGBM, age, rugosity, mean $\mathrm{DBH}$, and percent canopy cover. The open diamonds represent the error median, and the line represents the error average. For the purposes of this study we deem error median and means of less than $\pm 25 \mathrm{Mg}$ /ha with an associated 10th-90th percentile error range of $<50 \mathrm{Mg} / \mathrm{ha}$ to be areas for which the model is useful, error median and means of less than $\pm 50 \mathrm{Mg} / \mathrm{ha}$ with an associated 10th-90th percentile error range of $<100 \mathrm{Mg} / \mathrm{ha}$ to be areas for which the model is somewhat useful, and areas where the median and means of greater than $\pm 50 \mathrm{Mg} / \mathrm{ha}$ and associated 10th-90th percentile error ranges of $>100 \mathrm{Mg} / \mathrm{ha}$ to be areas for which the model does not perform well.

Due to the masking of zero AGBM data, the pixels that would normally fall into classes of zero or low AGBM, percent canopy cover, age, DBH, or canopy height often have a 

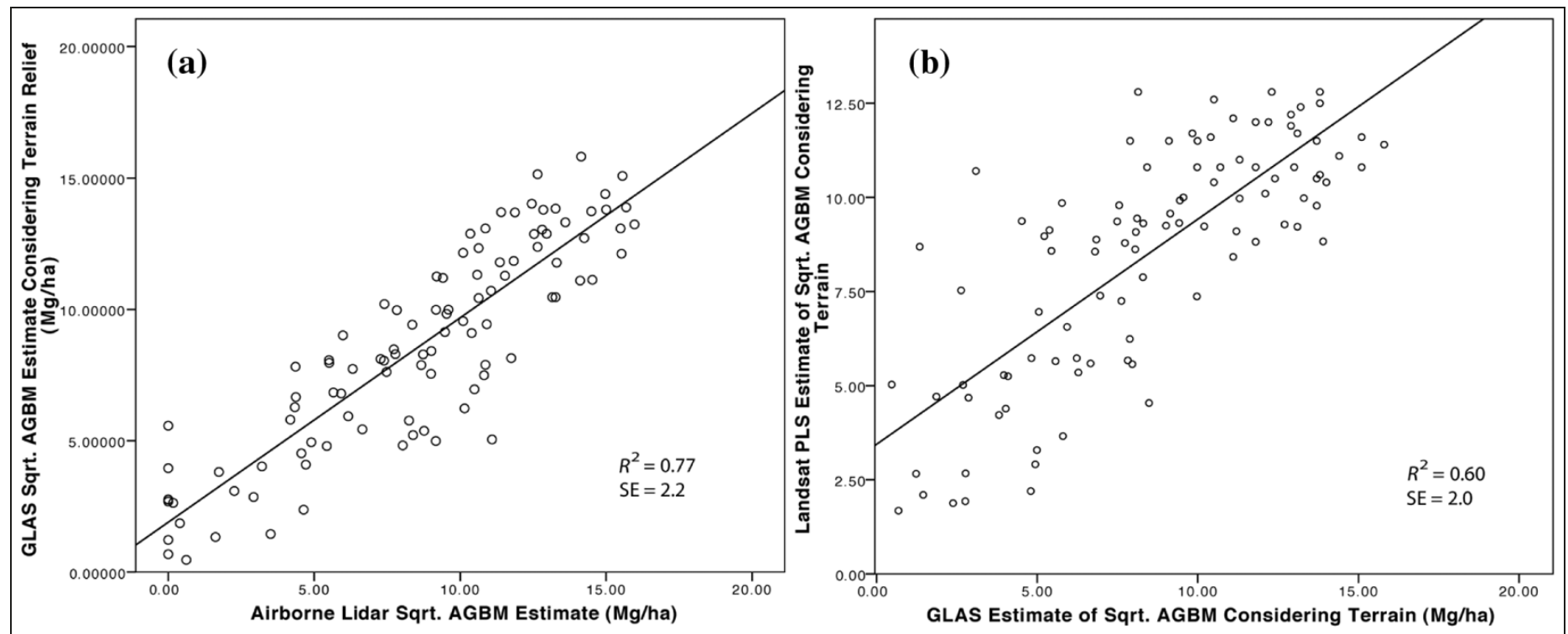

Figure 3. Results from (a) the GLAS model and (b) the Landsat-GLAS model. The GLAS model estimates the square root (Sqrt.) of observed airborne lidar AGBM using GLAS waveform metrics, and the Landsat-GLAS model estimates the square root of GLAS AGBM estimates using Landsat bands $1-5$ and 7.

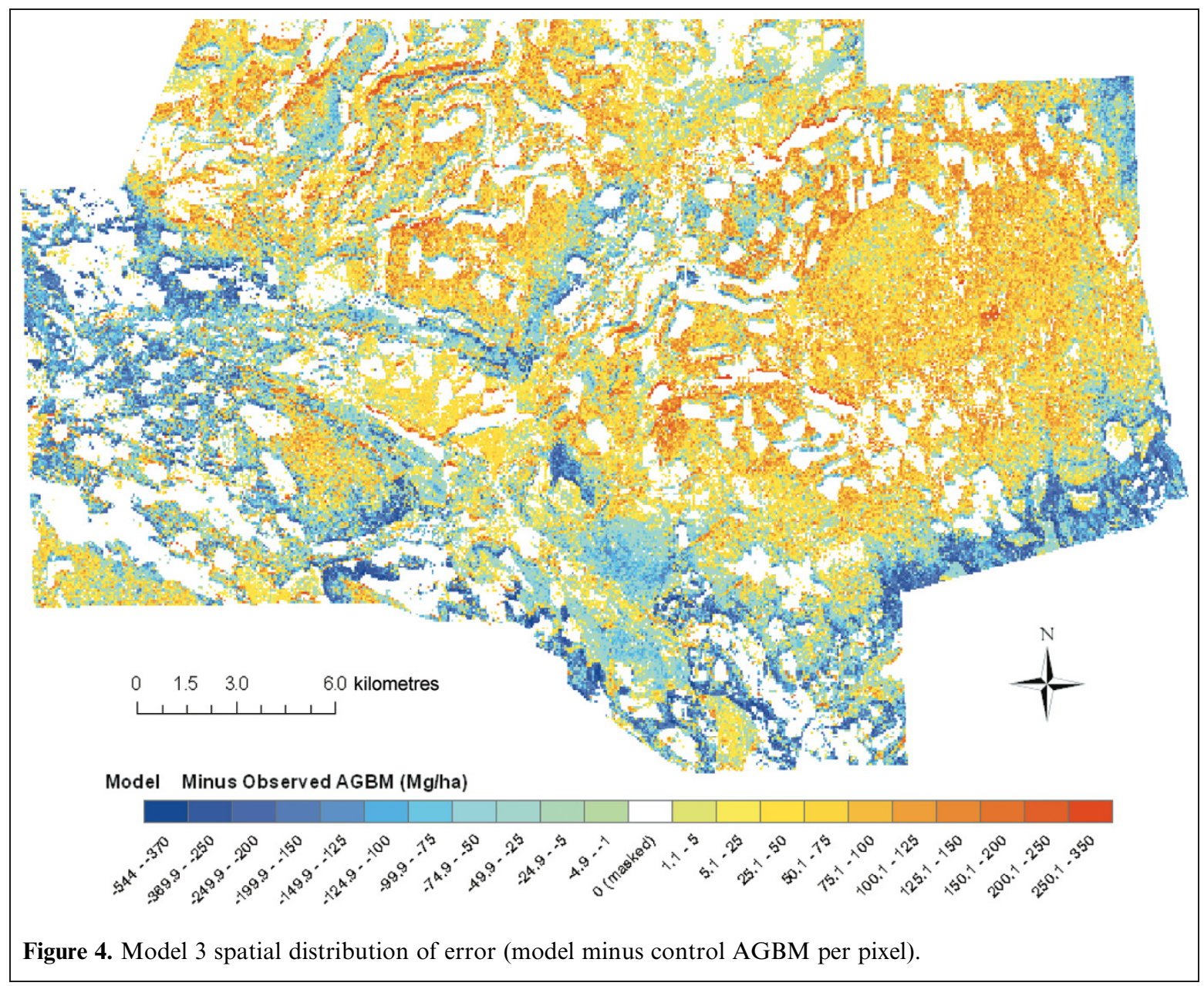




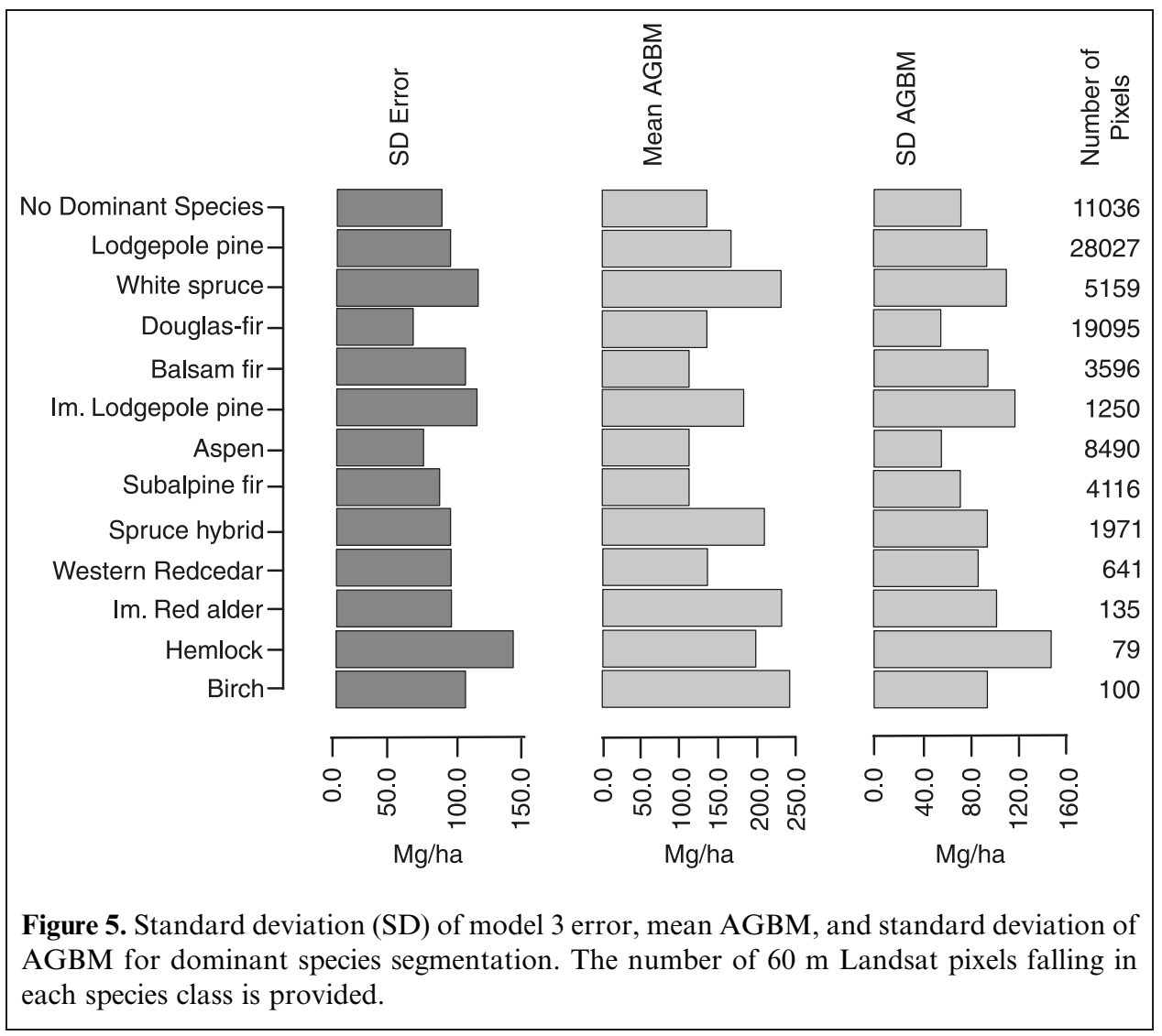

pixel value of "no data." The class divisions and number of pixels within each class are shown in Table 3. There is an overestimate of approximately $30 \mathrm{Mg} / \mathrm{ha}$ of AGBM when AGBM is less than approximately $120 \mathrm{Mg} /$ ha (Figure 6b). After $200 \mathrm{Mg} / \mathrm{h}$ a of AGBM, there is an average underestimation of greater than $100 \mathrm{Mg} / \mathrm{ha}$ of $\mathrm{AGBM}$, and the average underestimation increases to $200 \mathrm{Mg} / \mathrm{ha}$ after $300 \mathrm{Mg} / \mathrm{ha}$ of AGBM.

The relationship between age and model error is more complicated than many of the other relationships (Figure 6c). Forests between 1 and 40 years of age have relatively small error distributions (less than $\pm 100 \mathrm{Mg} / \mathrm{ha}$ ), and AGBM has an average overestimate of approximately $15 \mathrm{Mg} /$ ha. Between 41 and 60 years of age, the model overestimates AGBM by an average of only $2 \mathrm{Mg} / \mathrm{ha}$, but the distribution of error is $\pm 100 \mathrm{Mg} / \mathrm{ha}$. Between 61 and 120 years of age, the model underestimates AGBM, as do forests older than 250 years, and these have the widest range of errors. Interestingly, stands between 141 and 250 years of age show overestimates of AGBM and narrower error distributions.

The model overestimated AGBM when canopy height was less than $20 \mathrm{~m}$ (by approximately $20 \mathrm{Mg} / \mathrm{ha}$ ) or greater than $30 \mathrm{~m}$ (by approximately $5 \mathrm{Mg} / \mathrm{ha}$ ). The distribution of error increases by $21 \mathrm{Mg} / \mathrm{ha}$ in canopies ranging from 11 to $20 \mathrm{~m}$ and by $32 \mathrm{~m}$ for stands with canopies greater than $20 \mathrm{~m}$ high. The model was somewhat useful for canopies less than $20 \mathrm{~m}$ and greater than $20 \mathrm{~m}$ high.
As mean DBH increases so does the distribution of error (Figure 6e); however, DBH does not appear to be a useful characteristic by which to divide the study area because the model performs poorly in all but the $0-10 \mathrm{~cm} \mathrm{DBH}$ class, for which it is only somewhat useful. Similarly, the overall increase in error distribution associated with increases in vertical complexity of the forest (rugosity) is $50 \mathrm{Mg} / \mathrm{ha}$, and the model performs poorly in all but the lowest rugosity classes.

Canopy cover yields a different relationship with model error (Figure 6f). The model is somewhat successful between $0 \%$ and $20 \%$ canopy cover, performs well between $20 \%$ and $40 \%$ canopy cover, is somewhat successful between $40 \%$ and $60 \%$ canopy cover, and performs poorly after $60 \%$ canopy cover. The exception, however, is for the class of $90 \%-100 \%$ canopy cover, for which the model performs well.

\section{Discussion}

\section{GLAS AGBM estimation}

The GLAS estimates of AGBM compare favorably with those from other studies (Lefsky et al., 2005, $R^{2}=0.59-0.68$; Sun et al., 2007, $R^{2}=0.73$ ) which include high-AGBM areas $(>250 \mathrm{Mg} / \mathrm{ha}$ ). The relationship between GLAS waveform metrics and AGBM is linear, and error does not increase with increasing AGBM. These results reaffirm that GLAS is an appropriate tool for AGBM estimation. 

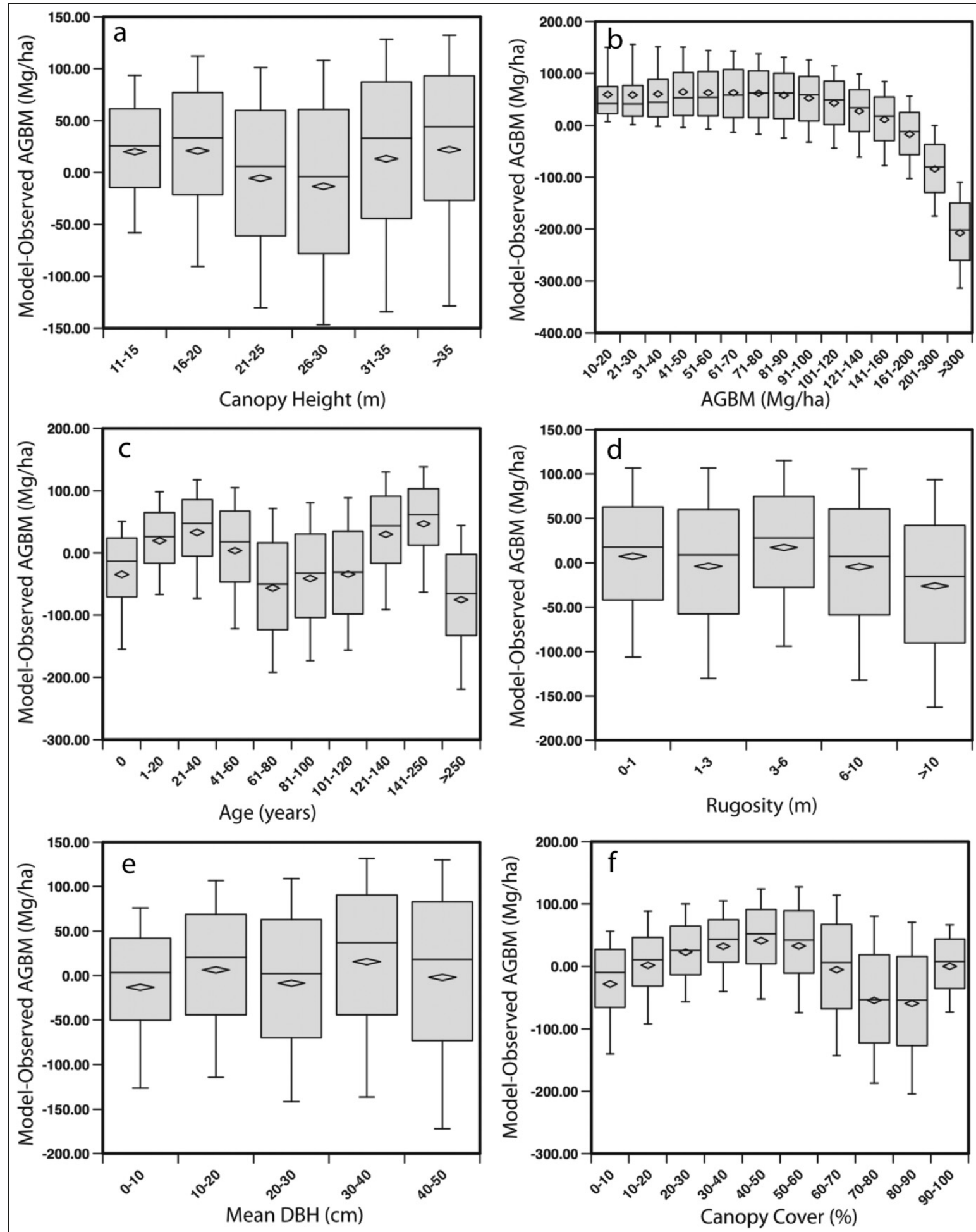

Figure 6. Box and whiskers plots (10th-90th percentiles of error) decomposing pixel-based error into various forest parameter classes. Lines represent medians, and diamonds means.

\section{Landsat AGBM estimation}

The utility of GLAS and Landsat integration depends on the characteristics of the landscape, as seen in Figure 6. The applicability of these methods depends on the assumption that the relationship between AGBM and vegetation spectral response is consistent between the transect sensed by GLAS and the study area. The highest biomass areas fall outside of the GLAS transect, which may explain the trend to underestimating the AGBM in the study area by the Landsat- 
Table 3. Number of pixels in various forest classes as used in Figure 6.

\begin{tabular}{|c|c|}
\hline Class & No. of pixels \\
\hline \multicolumn{2}{|c|}{ Rugosity (m) } \\
\hline $0-1.0$ & 1480 \\
\hline $1.1-3.0$ & 11868 \\
\hline $3.1-6.0$ & 35254 \\
\hline $6.1-10.0$ & 27026 \\
\hline$>10.0$ & 2055 \\
\hline \multicolumn{2}{|c|}{ Mean DBH (cm) } \\
\hline $0-10.0$ & 35510 \\
\hline $10.1-20.0$ & 15140 \\
\hline $21.1-30.0$ & 35255 \\
\hline $30.1-40.0$ & 26078 \\
\hline$>40.0$ & 795 \\
\hline \multicolumn{2}{|c|}{ AGBM (Mg/ha) } \\
\hline $0-20$ & 910 \\
\hline $21-30$ & 3269 \\
\hline $31-40$ & 3620 \\
\hline $41-50$ & 4447 \\
\hline $61-70$ & 5224 \\
\hline $71-80$ & 6258 \\
\hline $81-90$ & 6652 \\
\hline $91-100$ & 6955 \\
\hline $101-120$ & 13439 \\
\hline $121-140$ & 11667 \\
\hline $141-160$ & 9738 \\
\hline $161-200$ & 14983 \\
\hline $201-300$ & 22733 \\
\hline$>300$ & 7454 \\
\hline \multicolumn{2}{|c|}{ Percent CC } \\
\hline $0-10.0$ & 5 \\
\hline $10.1-20.0$ & 1000 \\
\hline $20.1-30.0$ & 5080 \\
\hline $30.1-40.0$ & 11701 \\
\hline $40.1-50.0$ & 18870 \\
\hline $50.1-60.0$ & 18970 \\
\hline $60.1-70.0$ & 11716 \\
\hline $70.1-80.0$ & 5464 \\
\hline $80.1-90.0$ & 3186 \\
\hline $90.1-100.0$ & 1691 \\
\hline \multicolumn{2}{|l|}{ Age (years) } \\
\hline 0 & 23429 \\
\hline $1-20$ & 8871 \\
\hline $21-40$ & 6081 \\
\hline $41-60$ & 6919 \\
\hline $61-80$ & 7291 \\
\hline $81-100$ & 12518 \\
\hline $101-120$ & 7267 \\
\hline $121-140$ & 33304 \\
\hline $141-250$ & 7098 \\
\hline$>250$ & 369 \\
\hline \multicolumn{2}{|c|}{ Canopy height (m) } \\
\hline $0-15.0$ & 3772 \\
\hline $15.1-20.0$ & 1769 \\
\hline $20.1-25.0$ & 15323 \\
\hline $25.1-30.0$ & 21613 \\
\hline $30.1-35.0$ & 16450 \\
\hline$>35.0$ & 16437 \\
\hline
\end{tabular}

GLAS model developed in this study. However, from deconstructing the scene into biomass classes, it was observed that the underestimation of AGBM began at approximately $140 \mathrm{Mg} / \mathrm{ha}$, within the AGBM range sampled by the GLAS transect. Therefore we believe that, although transect sampling may have empirically influenced the AGBM estimates, this influence was not sufficiently notable to alter the results or conclusions of this study. The underestimation exhibited across the study area in areas of greater than $120 \mathrm{Mg} / \mathrm{ha}$ AGBM is likely due to the spectral similarity of forests in these higher AGBM classes.

Partial least squares regression was found to be a reliable estimation technique for AGBM estimation from Landsat and GLAS data integration. This is attributed to the ability to include more input variables in PLS than in methods such as OLS regression, regardless of collinearity among input variables. All six Landsat bands were used as inputs to the PLS models, although the inclusion of NDVI or any of the tassel cap bands did not improve the model.

There were pixels with errors of $\pm 100 \mathrm{Mg} / \mathrm{ha}$ AGBM even in structural classes for which the model was most successful. This wide range of error is likely related to both the limitations associated with the utility of TM data for AGBM estimation (i.e., saturation effects) and the lowered observable variance associated with satellite-based estimates that are incapable of documenting the variance observed with high-resolution airborne data. This second issue is largely related to the spatial resolution of data. Spectral signals related to areas with mixtures of high and low biomass are aggregated to moderate levels of biomass, resulting in large underpredictions and overpredictions dependent on the resampling of imagery. Future satellite lidar missions (e.g., DesDynI) will have smaller footprint sizes, which may eliminate the need to aggregate Landsat data to $60 \mathrm{~m}$. This may increase the utility of spaceborne lidar integration with Landsat, although it is unlikely that this will increase the utility of Landsat for areas of AGBM greater than $140 \mathrm{Mg} /$ ha due to the spectral similarity of high-biomass forests.

\section{Error decomposition}

The standard deviation of error in the Landsat-GLAS model was the statistic deemed most indicative of model performance, as it enables a description of the breadth of error distribution. The wide range of AGBM values (0$612 \mathrm{Mg} / \mathrm{ha}$ ) in this study area likely increased the distribution of errors.

Figure 5 shows the standard deviation of the LandsatGLAS model error and the mean and standard deviation of AGBM. The large error associated with Douglas-fir and immature lodgepole pine may be site specific to our study area. Douglas-fir were present in the most underpredicted areas and are representative of old-growth stands ( $>250$ years) that are known to have variable AGBM in the study area. Immature lodgepole pine stands likely had spectral signatures similar to those of older, higher biomass 
members of their species that were prevalent across the landscape. The areas of immature lodgepole pine tended to be overestimated, although some were also underestimated, which likely caused the high standard deviation of error for this species.

The lower standard deviations of error associated with balsam fir, subapline fir, and white spruce may be related to the low mean and standard deviation of AGBM associated with these areas, and therefore also may have been site specific. Although GLAS estimates for these areas were likely successfully extrapolated, the model may not have performed as well if these species had been more prevalent in higher AGBM areas. Additionally, the field validation of the airborne lidar AGBM estimates was conducted almost exclusively within conifer forests, which may have influenced the accuracy of AGBM estimates in broadleaf environments.

Despite differences between the error distributions associated with different dominant species, the model did not perform well for any of the species divisions. It performed slightly better for conifer forests, but individual species results indicate that it is not the species of forest that determines the utility of the AGBM modeling approach developed in this study. Instead, the forest structural characteristics have a stronger relationship with model error, and researchers should focus on assessing these characteristics rather than species composition when considering applying similar methodologies.

The relationships between forest properties and error show that modeling AGBM using Landsat is more appropriate for forested environments with less than $120 \mathrm{Mg} / \mathrm{ha}$ of AGBM and that the conditions of a forest should be known prior to the application of these methods. Figure $\mathbf{6}$ shows a visualization of six relationships between increasing forest structural metrics and the distribution of error in each structure division.

\section{Canopy height, DBH, and rugosity}

The Landsat-GLAS model, as expected, was more successful for shorter canopies because these are typically less complex and will have a lower proportion of understory and shaded trees, for which Landsat data are less useful. The majority of AGBM in this study area is stored in the boles of the larger trees, and the smaller understory trees will contribute to the Landsat signal disproportionately to their AGBM contribution. However, canopy height was less useful for differentiating between model performance than other structural characteristics, indicating that it has a weak relationship with model performance. After $20 \mathrm{~m}$ of canopy height, the model performs poorly, regardless of canopy height increases. This indicates that either GLAS or, more likely, Landsat data are not useful for differentiation of canopies greater than $20 \mathrm{~m}$ high.

Similarly, the model only performed somewhat well for the smallest trees with DBH values between 0 and $10 \mathrm{~cm}$. We believe that DBH is not a controlling factor to the utility of the Landsat-GLAS model. Larger trees have higher associated error, but even small trees $(\mathrm{DBH}=10-30 \mathrm{~cm})$ are associated with high error and wide error distributions. This may be attributed to the fact that small-DBH trees are typically found in young, immature forests with a high density of trees. The spectral response from these actively growing forests may be indistinguishable from that of older forests with an active understory combined with large, productive canopies.

Rugosity is a measure of the vertical complexity of the canopy and is the square root of the variance of the standard deviation of lidar hits height. We expected that vertical complexity would play a significant role in the success of our models. However, there was no consistent trend as rugosity increased, and the model performed somewhat well or poorly across the rugosity classes. There appears to be a slight increase in the distribution as rugosity increases, but the results are generally inconclusive.

\section{AGBM}

The trend between error and AGBM is the most noteworthy trend portrayed in Figure 6. The results indicate that these methods should not be used to estimate AGBM for forests with values greater than $200 \mathrm{Mg} / \mathrm{ha}$ and should be used with caution for forests with ranges between 120 and $200 \mathrm{Mg} / \mathrm{ha}$. This depends on the information needs of an AGBM evaluation.

As expected, a saturation threshold of AGBM was apparent, after which Landsat spectral signals are indistinguishable with increasing AGBM. In this study this saturation point appears to be between 120 and $200 \mathrm{Mg} / \mathrm{ha}$.

\section{Age}

The relationship between age and model error is more complicated than many of the other relationships. These age divisions were taken from the divisions provided in the forest inventory. Forests of age " 0 " are likely recently clearcut or planted stands or nonforest environments that fell outside the zero-AGBM mask and may not be appropriately comparable with the lidar data. The relationship between forest age and Landsat-GLAS model error is likely a function of the relationship between age and AGBM itself. Therefore age may only be a useful variable for approximating AGBM when AGBM information is unavailable. A comparison of the observed AGBM map and the inventory-age map showed that biomass increased with age until approximately $61-80$ years. After this age, biomass no longer had a clear relationship with age; some of the highest biomass pixels were between 61 and 80 years of age, and some of the oldest stands had biomass values as low as $100 \mathrm{Mg} / \mathrm{ha}$. These old, lower biomass stands may have been affected by disturbances such as wind damage. Consequently, if a forest stand is older than approximately 60 years, Landsat data may be useful for AGBM estimation, but this is dependent on other forest structural properties, and not age in particular. 


\section{Percent canopy cover}

The decrease in model accuracy after approximately $60 \%$ canopy cover is likely related to the relationships between age, canopy cover, and AGBM in the study area. An analysis of the associated maps shows that canopy covers greater than $60 \%$ typically correspond to stand ages of $41-140$ years. Older canopies typically have a canopy cover of $50 \%-60 \%$, and younger stands have $<50 \%$ canopy cover. Similarly, the AGBM over $60 \%$ canopy cover varies independently of canopy cover, whereas lower values of canopy cover are related to AGBM; $60 \%$ canopy cover has an associated AGBM of approximately $140 \mathrm{Mg} / \mathrm{ha}$. As a consequence, canopy cover may be a useful measure for determining whether Landsat is useful for AGBM estimation if an ancillary estimate of AGBM itself is not available.

\section{Conclusion}

Landsat and GLAS integration may be useful for biomass estimation when funding or logistical limitations prevent extensive data collection. The advantage of these data types is that they are freely available and have near-global coverage. These methods offer an improvement over some carbon estimation methods, such as biome-based AGBM extrapolations, which are the only estimation technique available for many remote areas of tropical forest (Gibbs et al., 2007).

The strength of this study was its ability to test empirically derived models in a spatially contiguous area outside of the dataset from which they were generated. Our first objective was to develop a method to model AGBM from GLAS and Landsat integration. This was achieved, and it was determined that the best method was to develop a PLS model of GLAS-estimated AGBM using the optical Landsat bands $1-5$ and 7 .

Our second objective was to determine the relationships between model error and forest cover properties, and we conclude that model performance varies between broadleaf and coniferous forests. The model estimates are more accurate in areas with lower average AGBM and lower standard deviation of AGBM because these simpler forests yield spectral responses below the documented saturation level for Landsat.

Our third objective was to establish ranges of forest structural properties for which these methods are most appropriate. We determined that AGBM was the best indicator of model applicability, with optimal model performance corresponding to areas with less than $120 \mathrm{Mg} / \mathrm{ha}$ AGBM. These models may also perform well in areas with between 120 and $200 \mathrm{Mg} / \mathrm{ha}$ AGBM. Forest age and percent canopy cover may also be useful indicators of model applicability, with $60 \%$ canopy cover and 60 years of age acting as thresholds under which the model performs well. However, if AGBM is higher than $120 \mathrm{Mg} / \mathrm{ha}$, this method should be used with caution even in young forests or forests with $>60 \%$ canopy cover. These methods may be appropriate above these thresholds depending on the required accuracy of AGBM estimation.

Additionally, the models presented in this paper are more accurate in conifer forests. This may be due to the favouring of conifer plots in the validation of the airborne lidar and because the majority of the study site is forested by conifers. For forests outside the recommended range of conditions, we believe the use of satellite-based multispectral data will limit the accuracy of AGBM estimation.

\section{References}

Cai, T., Ju, C., and Yang, X. 2009. Comparison of ridge regression and partial least squares regression for estimating above-ground biomass with Landsat images and terrain data in Mu US Sandy Land, China. Arid Land Research and Management, Vol. 23, pp. 248-261. doi:10.1080/ 15324980903038701.

Clark, M.L., Roberts, D.A., and Clark, D.B. 2005. Hyperspectral discrimination of tropical rain forest tree species at leaf to crown scales. Remote Sensing of Environment, Vol. 96, pp. 375-398. doi:10.1016/j.rse.2005.03.009.

Cohen, W.B., and Spies, T.A. 1992. Estimating structural attributes of Douglas-fir/western hemlock forest stands from Landsat and SPOT imagery. Remote Sensing of Environment, Vol. 41, pp. 1-17. doi:10.1016/00344257(92)90056-P.

Cohen, W.B., Maiersperger, T.K., Gower, S.T., and Turner, D.P. 2003. An improved strategy for regression of biophysical variables from Landsat ETM+ data. Remote Sensing of Environment, Vol. 84, pp. 561-571. doi:10.1016/S0034-4257(02)00173-6.

Donoghue, D.N.M., and Watt, P.J. 2006. Using lidar to compare forest height estimates from IKONOS and Landsat ETM+ data in Sitka spruce plantation forests. International Journal of Remote Sensing, Vol. 27, pp. 2161-2175.

Duncanson, L.I., Niemann, K.O., and Wulder, M.A. 2010. Estimating forest canopy height and terrain relief from GLAS waveform metrics. Remote Sensing of Environment, Vol. 114, No. 1, pp. 138-154. doi:10. 1016/j.rse.2009.08.018

Foody, G.M., Cutler, M.E., McMorrow, J., Pelz, D., Tangka, H., Boyd, D.S., and Douglas, I. 2001. Mapping the biomass of Bornean tropical rain forest from remotely sensed data. Global Ecology and Biogeography, Vol. 10, pp. 379-387. doi:10.1046/j.1466-822X.2001.00248.x.

Freitas, S.R., Mello, M.C.S., and Cruz, C.B.M. 2005. Relationships between forest structure and vegetation indices in Atlantic Rainforest. Forest Ecology and Management, Vol. 218, pp. 353-362. doi:10.1016/j.foreco.2005. 08.036 .

Gibbs, H.K., Brown, S., Niles, J.O., and Foley, J.A. 2007. Monitoring and estimation tropical forest carbon stocks: making REDD a reality. Environmental Research Letters, Vol. 2, No. 045023. doi:10.1088/1748-9326/2/ $4 / 045023$.

Hall, R.J., and Case, B.S. 2008. Assessing prediction errors of generalized tree biomass and volume equations for the boreal forest region of westcentral Canada. Canadian Journal of Forestry Management, Vol. 38, pp. 878-889. doi:10.1139/X07-212.

Hall, F.G., Shimabukuro, Y.E., and Huemmrich, K.F. 1995. Remote sensing of forest biophysical structure using mixture decomposition and geometric reflectance models. Ecological Applications, Vol. 5, pp. 993-1013. doi:10.2307/2269350. 
Hall, R.J., Skakun, R.S., Arsenault, E.J., and Case, B.S. 2006. Modeling forest stand structure attributes using Landsat ETM+ data: Application to mapping of aboveground biomass and stand volume. Forest Ecology and Management, Vol. 225, pp. 378-390. doi:10.1016/j.foreco.2006.01.014.

Han, T., Wulder, M.A., White, J.C., Coops, N.C., Alvarez, M.F., and Butson, C. 2007. An efficient protocol to process Landsat images for change detection with tasseled cap transformation. Geoscience and Remote Sensing Letters, Vol. 4, pp. 147-151. doi:10.1109/LGRS.2006.887066.

Hensen, P.M., and Schjoerring, J.K. 2003. Reflectance measurement of canopy biomass and nitrogen status in wheat crops using normalized vegetation indices and partial least squares regression. Remote Sensing of Environment, Vol. 86, pp. 542-553. doi:10.1016/S0034-4257(03)00131-7.

Hudak, A.T., Lefsky, M.A., Cohen, W.B., and Berterretche, M. 2002. Integration of lidar and Landsat ETM+ data for estimating and mapping forest canopy height. Remote Sensing of Environment, Vol. 82, pp. 397416. doi:10.1016/S0034-4257(02)00056-1.

Jenkins, J.C., Chojnacky, D.C., Heath, L.S., and Birdsey, R.A. 2003. National-scale biomass estimators for United States tree species. Forest Science, Vol. 49, pp. 12-35.

Lefsky, M.A., Harding, D.J., Keller, M., Cohen, W.B., Carabajal, C.C., Espirito-Santo, F.D.B., Hunter, M.O., and de Oliveira, R., Jr. 2005. Estimates of forest canopy height and aboveground biomass using ICESat. Geophysical Research Letters, Vol. 32, L22S02. doi:10.1029/2005GL023971.

Lefsky, M.A., Keller, M., Pang, Y., de Camargo, P.B., and Hunter, M.O. 2007. Revised method for forest canopy height estimation from Geoscience Laser Altimeter System waveforms. Journal of Applied Remote Sensing, Vol. 1, No. 013537. doi:10.1117/1.2795724.

Means, J.E., Acker, S.A., Harding, D.J., Blair, J.B., Lefsky, M.A., Cohen, W.B., Harmon, M.E., and McKeww, W.A. 1999. Use of large-footprint scanning airborne LiDAR to estimate forest stand characteristics in the Western Cascades of Oregon. Remote Sensing of Environment, Vol. 67, pp. 298-308. doi:10.1016/S0034-4257(98)00091-1.

Ministry of Sustainable Resource Management. 2003. Vegetation resources inventory: quality assurance procedures for VRI ground sampling. Resources Information Standards Committee, Ministry of Sustainable Resource Management, Victoria, B.C.

Næsset, E., Bollandsas, O.M., and Gobakken, T. 2004. Comparing regression methods in estimation of biophysical properties of forest stands from two different inventories using laser scanner data. Remote Sensing of Environment, Vol. 28, pp. 541-553.

Nelson, R., Valenti, M.A., Short, A., and Keller, C. 2003. A multiple resource inventory of Delaware using airborne laser data. BioScience, Vol. 53, pp. 981-992. doi:10.1641/0006-3568(2003)053[0981:AMRIOD]2.0.CO;2.

Patenaude, G., Hill, R.A., Milne, R., Gaveau, D.L.A., Briggs, B.B.J., and Dawson, T.P. 2004. Quantifying forest above ground carbon content using LiDAR remote sensing. Remote Sensing of Environment, Vol. 93, pp. 368-380. doi:10.1016/j.rse.2004.07.016.

Pedersen, L., and Forester, C. 2000. Tree farm license 18: rationale for allowable annual cut (AAC) determination. British Columbia Ministry of Forests, Victoria, B.C.

Ranson, K.J., Kimes, D., Sun, G., Nelson, R., Khaaruk, V., and Montesano, P. 2007. Using MODIS and GLAS data to develop timber volume estimates in central Siberia. In IGARSS'07: Proceedings of the International Geoscience and Remote Sensing Symposium, 23-26 July 2007, Barcelona, Spain. IEEE, Piscataway, N.J. pp. 2306-2309.

Rogan, J., Franklin, J., and Roberts, D.A. 2002. A comparison of methods for monitoring multitemporal vegetation change using Thematic Mapper imagery. Remote Sensing of Environment, Vol. 80, pp. 143-156. doi:10. 1016/S0034-4257(01)00296-6.

Rosenqvist, A., Milne, A., Lucas, R., Imhoff, M., and Dobson, C. 2003. A review of remote sensing technology in support of the Kyoto Protocol. Environmental Science and Policy, Vol. 6, pp. 441-455. doi:10.1016/ S1462-9011(03)00070-4.

Rosette, J.A.B., North, P.R.J., and Suarez, J.C. 2008. Vegetation height estimates for a mixed temperate forest using satellite laser altimetry. International Journal of Remote Sensing, Vol. 29, pp. 1475-1493. doi:10.1080/01431160701736380.

Schutz., B.E., Zwally, H.J., Shuman, C.A., Hancock, D., and DiMarzio, J.P. 2005. Overview of the ICESat Mission. Geophysical Research Letters, Vol. 32, L21S01.

Sprugel, D.G. 1983. Correcting for bias in log-transformed allometric equations. Ecology, Vol. 64, pp. 209-210. doi:10.2307/1937343.

Sun, G., Ranson, K.J., Masek, J., Fu, A., and Wang, D. 2007. Predicting tree height and biomass from GLAS data. In Proceedings of the 10th International Symposium on Physical Measurements and Signatures in Remote Sensing (ISPMSRS'07), 12-14 March 2002, Davos, Switzerland. Edited by M.E. Schaepman, S. Liang, N.E. Groot, and M. Kneubuhler. ITC, Enschede, The Netherlands.

Sun, G., Ranson, K.J., Kimes, D.S., Blair, J.B., and Kovacs, K. 2008. Forest vertical structure from GLAS: An evaluation using LVIS and SRTM data. Remote Sensing of Environment, Vol. 112, pp. 107-117. doi:10. 1016/j.rse.2006.09.036.

Van Aardt, J.A.N., and Wynne, R.H. 2007. Examining pine spectral separability using hyperspectral data from an airborne sensor: an extension of field-based results. International Journal of Remote Sensing, Vol. 28, pp. 431-436. doi:10.1080/01431160500444772.

Wulder, M. 1998. Optical remote-sensing techniques for the assessment of forest inventory and biophysical parameters. Progress in Physical Geography, Vol. 22, pp. 449-476.

Wulder, M.A., and Seemann, D. 2003. Forest inventory height update through the integration of lidar data with segmented Landsat imagery. Canadian Journal of Remote Sensing, Vol. 29, No. 5, pp. 536-543.

Wulder, M.A., Han, T., White, J.C., Sweda, T., and Tsuzuki, H. 2007. Integrating profiling LiDAR with Landsat data for regional boreal forest canopy attribute estimation and change characterization. Remote Sensing of Environment, Vol. 110, No. 1, pp. 123-137. doi:10.1016/j.rse.2007.02.002.

Wulder, M.A., Bater, C.W., Coops, N.C., Hilker, T., and White, J.C. 2008. The role of lidar in sustainable forest management. The Forestry Chronicle, Vol. 84, No. 6, pp. 807-826.

Zheng, D., Rademacher, J., Chen, J., Crow, T., Bresse, M., Le Moine, J., and Ryu, S.R. 2004. Estimating aboveground biomass using Landsat 7 ETM+ data across a managed landscape in northern Wisconsin, USA. Remote Sensing of Environment, Vol. 93, pp. 402-411. doi:10.1016/j.rse.2004.08.008. 